\title{
Challenges to improve the nutritional quality of foods served by small independent takeaway outlets
}

\author{
T.M. Blackham ${ }^{1}$, A. Hands ${ }^{2,3}$, P. Hargrave ${ }^{3}$, I.G. Davies ${ }^{1}$, L. Stevenson ${ }^{1}$, \\ V. $\operatorname{Cox}^{2}$ and A. Coufopoulos \\ ${ }^{1}$ Food, Nutrition and Health Research Group, Liverpool John Moores University, L17 6BD, ${ }^{2}$ Coventry University, \\ CV1 $5 F B$ and ${ }^{3}$ Coventry City Council, CV1 5RS.
}

Takeaway foods are a popular meal choice, with previous research from Liverpool showing $48 \cdot 3 \%$ of respondents eating takeaway food once or twice a month and $22 \%$ once or twice a week ${ }^{(1)}$. More recent data collected in Coventry, showed rates of consumption which were even higher, with $50 \%$ of respondents eating takeaway meals once or twice a week ${ }^{(2)}$. Nutrient analysis has suggested high levels of energy, fat, saturated fat, and salt in many types of takeaway foods ${ }^{(3)}$ and the frequent consumption of such foods is also linked to overweight and obesity ${ }^{(4)}$.

'Eating Out Coventry' was a collaborative healthy catering project which worked with small independent takeaway outlets in deprived areas of Coventry. The aim of the project was to improve the nutritional quality of takeaway food. Twenty-seven outlets were targeted in Coventry and surrounding areas; often involving numerous visits by the research team. The project focused on a few key manageable changes such as providing smaller portion sizes; offering healthier options, such as boiled or steamed rice / jacket potatoes / salad; introducing 5-hole salt shakers; adding salt only when the customer requests it; adapting recipes to use less salt, fat or sugar; and adopting frying practices to reduce fat absorption. Outlets were asked to complete a questionnaire, display a poster to show customers their "Commitments" and supplied with a takeaway resource toolkit.

\begin{tabular}{lcc}
\hline Outlet Type & $\begin{array}{c}\text { Agreed to Participate } \\
(\mathrm{n}=9)\end{array}$ & $\begin{array}{c}\text { Completed Final Stage of Project } \\
(\mathrm{n}=4)\end{array}$ \\
\hline Fish and Chips & 4 & 2 \\
Chinese & 3 & 1 \\
Indian & 2 & 1 \\
\hline
\end{tabular}

Whilst the project started out with the intention of improving the healthfulness of takeaway food served by small independent takeaway outlets, in practice this was quite difficult to achieve. While formal inferential statistics are not relevant, the following descriptive data shows: one outlet added salad in pitta bread to its menu, now offers salad as an alternative to chips and offers smaller portions. At another outlet, customers were frustrated with the server using 5-hole salt shakers, and preferred 17-hole salt shakers.

Takeaway outlets were resistant to taking part and the project met with poor levels of engagement. The main reasons for not participating included: language barriers (majority of staff were non-English speaking); lack of available time (staff too busy, managers not available); outlets were difficult to reach and concerned with study burden. Many outlets described financial difficulties and fierce competition; there was also a perception that customers did not want healthier food and that healthier foods were more expensive. Some outlets were unwilling to make changes as they felt it would change the taste of the food they served and did not want to affect their profits (they were also worried that their active participation in the project might deter customers).

In summary, findings from this research study adds to the evidence that owners and managers of takeaway outlets can be hard to reach, and difficult to engage in voluntary public health interventions (which can be time-consuming and resource heavy). Well-resourced studies, involving academic, local authority and community representative partnerships are required. These projects should focus on changing the owners' understanding of healthy food, providing customer evidence and emphasising the potential economic advantages of healthier choices.

1. Blackham T et al. (2016) P Nutr Soc 75 (OCE3) E91.

2. Blackham T (2015) Coventry Public Engagement Exercise (Unpublished Results).

3. Jaworowska A, Blackham T, Long R et al. (2014) NFS 44 (5), 414430.

4. Burgoine T, Forouhi NG, Griffin SJ et al. (2014) BMJ 348, g1464. 